\title{
Association of Androgenetic Alopecia with Benign Prostatic Hyperplasia: A Case Control Study
}

\author{
Chaudhary MK ${ }^{1}$, Agrawal $\mathbf{S}^{1}$, Agrawal CS $^{2}$
}

${ }^{1}$ Department of Dermatology \& Venereology; ${ }^{2}$ Department of Surgery, B P Koirala Institute of Health Sciences, Dharan, Nepal

\begin{abstract}
Introduction: Androgenetic alopecia (AGA) is associated with increased risk of several systemic diseases and some environmental factors, however, controversies exist. Since AGA and Benign Prostatic Hyperplasia (BPH) share common pathogenesis and AGA manifests some decades before BPH onset, it may serve as an early marker of BPH.

Objective: This study was conducted to know AGA and its association with BPH in men $\geq 20$ years of age.

Materials and Methods: Clinically diagnosed cases of AGA ( $n=176)$ and 117 age matched healthy controls were enrolled. All cases and controls were subjected for abdomino-pelvic ultrasonography, urinary flowmetry, fasting lipid profiles, glycemic index and body mass index. International Prostate Symptom Score (IPSS) was also assessed.

Results: Among 176 patients, 120 (68.18\%) had Hamilton-Norwood grade III AGA and 56 (31.82\%) had grade IV-VII AGA. In both groups, 140 (79.55\%) cases and 93 (79.49\%) controls were aged $<35$ years respectively. Family history of AGA was present in $108(61.36 \%)$ cases and $2(1.71 \%)$ controls. This observation was statistically significant with $\mathrm{OR}=89.61(95 \% \mathrm{Cl} 23.67-339.29)$. Three (1.7\%) cases and none of the controls had prostate volume $>30 \mathrm{ml}$. Seventeen (9.66\%) cases and $4(3.42 \%)$ controls were graded as moderately/severely symptomatic IPSS. Statistically significant association was seen between family history and early onset of hair loss ( $<35$ years) in a male sibling or parent.

Conclusion: Although positive family history was associated with early onset of AGA, no association between AGA and BPH could be elicited in our study.

Key words: Alopecia; body mass index; glycemic index; lipids; prostatic hyperplasia
\end{abstract}

\section{Introduction}

A ndrogenetic alopecia (AGA) is a hereditary disorder, mediated by androgens and characterized by progressive patterned thinning of the scalp hair. ${ }^{1}$ The incidence and the severity of androgenetic alopecia is found to be highest in white men, second highest in Asians and African Americans, and lowest in Native Americans and Eskimos. Almost all patients have an onset by the age of 40 years, although many of the patients (both males and females) show evidence of AGA by the age of 30 years. $^{2}$

Although there are no serious direct health consequences, the loss of scalp hair allows ultraviolet light to reach the scalp and thus, increases risk of actinic damage. ${ }^{3}$ AGA has been shown to be associated

Address of Correspondence:

Dr. Manoj Kumar Chaudhary, MD

Assistant Professor

Department of Dermatology and Venereology

B P Koirala Institute of Health Sciences

Dharan, Nepal

E-mail: manojchaudhary12@live.com with increased risk of several diseases such as benign prostatic hyperplasia, ${ }^{4,5}$ hypertension, ${ }^{6}$ abnormal serum lipid profiles, ${ }^{6}$ obesity, ${ }^{6}$ insulin resistance, ${ }^{7,8}$ cardiovascular diseases, ${ }^{7}$ and some environmental factors such as smoking ${ }^{1}$ and stress. ${ }^{9}$ However, controversies exist regarding the association of those diseases and environmental factors with AGA. ${ }^{10,11}$

Submitted: $24^{\text {th }}$ December 2017

Accepted: $25^{\text {th }}$ February 2018

Published: $21^{\text {st }}$ March 2018

How to cite this article

Chaudhary MK, Agrawal S, Agrawal CS. Association of androgenetic alopecia with benign prostatic hyperplasia: A case control study. Nepal Journal of Dermatology Venereology and Leprology. 2018;16(1):17-23. doi: http://dx.doi.org/10.3126 /njdvl.v16i1.19399

\section{(c) (i)}

Licensed under CC BY 4.0 International License which permits use, distribution and reproduction in any medium, provided the original work is properly cited. 
Benign prostatic hyperplasia (BPH) is the commonest benign neoplasm in men aged 70 years and older with or without obstructive symptoms affecting more than $70 \%$ of men. ${ }^{4} \mathrm{BPH}$ is more common among elderly men but infrequent in age less than 40 years. Its prevalence increases above the age of 60 years. Androgen function and patients' age are important for the occurrence of $\mathrm{BPH} .^{5}$

Since AGA and BPH share common pathogenesis and AGA manifests some decades before BPH onset, it may serve as an early marker of $\mathrm{BPH}$.

\section{Materials and Methods}

The study was conducted in the outpatient department (OPD) of dermatology, BP Koirala Institute of Health Sciences, Dharan between 1st April 2013 and 31st March 2014. All clinically diagnosed cases of AGA $(n=176)$ and 117 age matched healthy controls were enrolled between $1^{\text {st }}$ April 2013 and 31st March 2014 in our study with prior informed and written consent. Ethical clearance was taken from the institutional ethical committee. Detail history about the disease, family history of AGA or $\mathrm{BPH}$, personal history of cardiovascular disease, hypertension, diabetes mellitus, alcoholism, cigarette smoking, lifestyle, drug intake was recorded in a preset proforma. Data regarding age, weight, height, waist circumference, body mass index, IPSS score were recorded. All cases and controls were subjected for abdomino-pelvic ultrasonography, urinary flowmetry, fasting lipid profiles and glycemic index measurement. The severity of baldness was also estimated from photographs taken at an anterior view, 900 tilt to the front side of the head, right and left 900 side views.

Statistical analyses were done using with Software SPSS (version 10.0 for Windows, SPSS Inc, Chicago, IL). The baseline characteristics of the study patients were expressed as numbers and percentages for categorical variables and as mean \pm standard deviation for continuous variables.

Qualitative variables were analyzed using $\chi 2$ test or the Fischer's exact test. A logistic regression model was employed to assess the associations between each possible risk factor (BPH, smoking, Body Mass Index, waist circumference, fasting plasma glucose, Blood Pressure (BP), and serum level of lipids, including Triglyceride (TG) and High Density Lipoprotein (HDL) and the risk of developing AGA (type III or greater). The statistical significance level was set at $5 \%$ for assessing each association, odds ratio (ORs) and their 95\% confidence intervals (Cls). The odds ratio was determined by the Wald Chi-square test, and predictors with $p<0.10$ were subsequently assessed using multivariate analyses with a forward stepwise selection procedure. The threshold of 0.05 was regarded as significant with the logistic model of regression.

\section{Results}

Total of 176 cases and 117 controls were analyzed in this study. The mean $\pm S D$ age of case and control groups were $29.40 \pm 8.74$ years and $29.62 \pm 9.47$ years, respectively.

In this study, $68.18 \%$ of population had Grade III AGA, followed by Grade IV (21.02\%). Majority of the population in the study followed Hindu religion in both the case and control groups (92.61\% vs. $89.55 \%)$ respectively. Sixty-three (35.8\%) cases and 48 (41.02\%) controls were married, and most of the population belonged to middle class family (Table 1). Emotional stress was found to be the commonest precipitating factor $(66.7 \%)$ in the cases. In this study, 100 (56.8\%) cases and 53 (45.29\%) controls lived non-sedentary life style.

The cases and control groups did not differ significantly in mean age (AGA, 29.40 years vs control, 30.30 years), age group $<35$ years vs $\geq 35$ years $(79.55 \% \& 20.45 \%$ vs $79.49 \%$ \& $20.51 \%, \mathrm{p}=0.99)$, marital status $(35.8 \%$ vs $41.03 \%, p=0.36)$, cigarette smoking $(37.5 \%$ vs $38.57 \%$, $\mathrm{p}=0.64)$. Mean BMI was found to be $23.87 \mathrm{~kg} / \mathrm{m}^{2}$ vs $25.67 \mathrm{~kg} / \mathrm{m}^{2}$ in case and control groups respectively. Waist circumference was $>90 \mathrm{~cm}$ in $1.1 \%$ cases and $7.69 \%$ controls. Mean Systolic blood pressure and mean diastolic blood pressure, mean cholesterol level, mean Triglyceride level, mean High density lipoprotein level and mean low density lipoprotein levels were comparable among the case and control groups (Table $2 \& 3)$.

Family history of AGA was present in 108 (61.36\%) patients and two controls (1.7\%). This was found to be statistically significant (OR=89.61; 95\% Cl 23.67339.29 and $p$ value $<0.001)$. First degree relatives of the patients had a positive family history of AGA in $44.8 \%$. Site of onset of AGA was frontal in $78.4 \%$ of the cases. Three $(1.7 \%)$ of the cases had prostate volume $>30 \mathrm{ml}$ and none of the patients in control group had prostate volume $>30 \mathrm{ml}$. Seventeen $(9.66 \%)$ patients and four $(3.42 \%)$ controls were graded as moderately/ severely symptomatic IPSS. 
In univariate analysis, there was no significant association found between the AGA and BPH, age $<35 y e a r s$, family history of $\mathrm{BPH}$, past treatment taken for other diseases, blood pressure, blood sugar level, prostate specific antigen, cigarette smoking, cholesterol, triglyceride, Low Density Lipoprotein (LDL) and HDL level. The family history of AGA and IPSS were significantly associated in cases as compared to controls and conversely BMI and Waist circumference was statistically significant in control group as compared to cases (Table 1). But in multivariate analysis, only family history of AGA was significantly associated with androgenetic alopecia in our study (Table 4).

Table 1. Clinical and laboratory parameters associated with Androgenetic Alopecia

\begin{tabular}{|c|c|c|c|}
\hline Variable & $\begin{array}{c}\text { Case } \\
n=176(\%)\end{array}$ & $\begin{array}{c}\text { Control } \\
n=117(\%)\end{array}$ & $p$ value \\
\hline $\begin{array}{l}\text { Age group (years) } \\
\quad<35 \\
\geq 35\end{array}$ & $\begin{array}{c}140(79.55) \\
36(20.45)\end{array}$ & $\begin{array}{l}93(79.49) \\
24(20.51)\end{array}$ & 0.990 \\
\hline $\begin{array}{l}\text { Marital Status } \\
\text { Unmarried } \\
\text { Married }\end{array}$ & $\begin{array}{c}113(64.2) \\
63(35.8)\end{array}$ & $\begin{array}{l}69(58.97) \\
48(41.03)\end{array}$ & 0.366 \\
\hline $\begin{array}{l}\text { Family History of AGA } \\
\text { No } \\
\text { Yes }\end{array}$ & $\begin{array}{c}68(38.64) \\
108(61.36)\end{array}$ & $\begin{array}{c}115(98.29) \\
2(1.71)\end{array}$ & $* 0.000$ \\
\hline $\begin{array}{l}\text { Family History of BPH } \\
\text { Yes } \\
\text { No }\end{array}$ & $\begin{array}{c}12(6.8) \\
164(93.2)\end{array}$ & $\begin{array}{c}9(7.69) \\
108(92.31)\end{array}$ & 0.776 \\
\hline $\begin{array}{l}\text { Body Mass Index }\left(\mathrm{kg} / \mathrm{m}^{2}\right) \\
>25 \\
\leq 25\end{array}$ & $\begin{array}{c}58(32.95) \\
118(67.05)\end{array}$ & $\begin{array}{l}65(55.56) \\
52(44.44)\end{array}$ & $<0.001$ \\
\hline $\begin{array}{l}\text { Waist Circumference (cms) } \\
>90 \\
\leq 90\end{array}$ & $\begin{array}{c}2(1.14) \\
174(98.86)\end{array}$ & $\begin{array}{c}9(7.69) \\
108(92.31)\end{array}$ & $* 0.003$ \\
\hline $\begin{array}{l}\text { Diastolic BP }(\mathrm{mm} \mathrm{Hg}) \\
>90 \\
\leq 90\end{array}$ & $\begin{array}{c}2(1.14) \\
174(98.86)\end{array}$ & $\begin{array}{c}3(2.56) \\
114(97.44)\end{array}$ & $* 0.355$ \\
\hline $\begin{array}{l}\text { High Density Lipoprotein (HDL) (mg/dl) } \\
\quad \leq 40 \\
>40\end{array}$ & $\begin{array}{c}50(28.41) \\
126(71.59)\end{array}$ & $\begin{array}{l}38(32.48) \\
79(67.52)\end{array}$ & 0.456 \\
\hline $\begin{array}{l}\text { Triglyceride }(\mathrm{Tg})(\mathrm{mg} / \mathrm{dl}) \\
\quad \geq 150 \\
<150\end{array}$ & $\begin{array}{c}26(14.8) \\
150(85.2)\end{array}$ & $\begin{array}{c}16(13.68) \\
101(86.32)\end{array}$ & 0.880 \\
\hline $\begin{array}{l}\text { IPSS } \\
\text { Moderately/ Severely symptomatic } \\
\text { Mildly symptomatic }\end{array}$ & $\begin{array}{c}17(9.66) \\
159(90.34)\end{array}$ & $\begin{array}{c}4(3.42) \\
113(96.58)\end{array}$ & $* 0.042$ \\
\hline
\end{tabular}

*Fischer's exact test

Table 2: Comparison of prostate volume in two groups.

\begin{tabular}{|c|c|c|c|}
\hline Prostate volume (ml) & $\begin{array}{c}\text { Case } \\
\mathbf{n = 1 7 6}(\%)\end{array}$ & $\begin{array}{c}\text { Control } \\
\mathbf{n = 1 1 7}(\mathbf{\%})\end{array}$ & $\begin{array}{c}\text { Total } \\
\mathbf{n}=\mathbf{2 9 3}(\%)\end{array}$ \\
\hline$>30$ & $3(1.7)$ & $0(0)$ & $3(1.37)$ \\
\hline$\leq 30$ & $173(98.3)$ & $117(100)$ & $289(98.63)$ \\
\hline
\end{tabular}


Table 3: Comparison of different variables among the type of AGA.

\begin{tabular}{|c|c|c|c|c|}
\hline \multirow{2}{*}{ Variable } & \multicolumn{3}{|c|}{ Hamilton-Norwood Grade } & \multirow{2}{*}{$p$ value } \\
\hline & Grade III n (\%) & Grade IV-VII n (\%) & Total & \\
\hline \multicolumn{5}{|l|}{ Age Group (years) } \\
\hline$<35$ & $102(57.95)$ & $38(21.59)$ & $140(79.54)$ & 0.015 \\
\hline$\geq 35$ & $18(10.22)$ & $18(10.22)$ & $36(20.46)$ & \\
\hline \multicolumn{5}{|l|}{ Smoking status } \\
\hline Never & $80(45.45)$ & $30(17.04)$ & $110(62.5)$ & 0.099 \\
\hline Smoker & $40(22.72)$ & $26(14.77)$ & $66(37.5)$ & \\
\hline \multicolumn{5}{|l|}{ Family history of AGA } \\
\hline No & $50(28.40)$ & $17(9.65)$ & $67(38.06)$ & 0.183 \\
\hline Yes & $70(39.77)$ & $39(22.15)$ & $109(61.93)$ & \\
\hline \multicolumn{5}{|l|}{ Waist circumference (cms) } \\
\hline$<90$ & $119(67.61)$ & $55(31.25)$ & $174(98.86)$ & *0.536 \\
\hline$\geq 90$ & $1(0.56)$ & $1(0.56)$ & $2(1.13)$ & \\
\hline \multicolumn{5}{|l|}{$\mathrm{BMI}\left(\mathrm{kg} / \mathrm{m}^{2}\right)$} \\
\hline$\leq 25$ & $90(51.13)$ & $27(15.34)$ & $117(66.47)$ & 0.001 \\
\hline$>25$ & 30 (17.04) & $29(16.47)$ & 59 (33.52) & \\
\hline \multicolumn{5}{|l|}{ Benign Prostaic Hyperplasia (cc) } \\
\hline$>30$ & $2(1.13)$ & $1(0.56)$ & $3(1.70)$ & $* 1.0$ \\
\hline$\leq 30$ & $118(67.04)$ & 55 (31.25) & $173(98.29)$ & \\
\hline \multicolumn{5}{|l|}{ Hypertension (mm Hg) } \\
\hline$\geq 140 / 90$ & $3(1.70)$ & $3(1.70)$ & $6(3.40)$ & $* 0.384$ \\
\hline$<140 / 90$ & $117(66.47)$ & $53(30.11)$ & $170(96.60)$ & \\
\hline \multicolumn{5}{|l|}{ Metabolic Syndrome } \\
\hline No & $120(68.18)$ & $54(30.68)$ & $174(98.86)$ & \\
\hline Yes & $0(0)$ & $2(1.14)$ & $2(1.14)$ & \\
\hline \multicolumn{5}{|l|}{ IPSS } \\
\hline Mildly symptomatic & $111(63.06)$ & $48(27.27)$ & $159(90.34)$ & 0.176 \\
\hline Moderately/ Severely symptomatic & $9(5.11)$ & $8(4.54)$ & $17(9.65)$ & \\
\hline
\end{tabular}

*Fischer's exact test

Table 4: Multivariate logistic regression analysis for AGA.

\begin{tabular}{|l|c|c|c|c|}
\hline & Coefficient & Odds Ratio & 95\% Cl & p value \\
\hline Family H/O AGA & 4.495 & 89.611 & $23.667-339.288$ & 0.000 \\
\hline Life style & -0.051 & 0.950 & $0.354-2.549$ & 0.920 \\
\hline BMI & 0.523 & 1.687 & $0.580-4.900$ & 0.336 \\
\hline Waist circumference (cm) & -0.422 & 0.656 & $0.075-5.706$ & 0.702 \\
\hline Hamilton-Norwood grade & 17.162 & 28403444.361 & $0.000->1.0$ & 0.914 \\
\hline IPSS & 1.069 & 2.911 & $0.386-21915$ & 0.299 \\
\hline
\end{tabular}

$\mathrm{Cl}=$ confidence interval

\section{Discussion}

Androgenetic alopecia (AGA) is associated with increased risk of several systemic diseases and some environmental factors, however, controversies exist. Androgens like Testosterone and Dihydrotestosterone are involved in diseases like AGA and BPH. The enzyme 5-alpha reductase, which transforms testosterone into DHT, plays a key role. In patients with AGA, scalp biopsy specimens have shown increased DHT concentrations and 5-alpha-reductase activity. ${ }^{12,13}$
In a study done by $\mathrm{Oh}$ et $\mathrm{al}^{14}, \mathrm{BPH}$ had strong association with higher grade of male pattern baldness than that of controls (median value of grade IV versus III, $p$ value $<0.001$ ). Similarly, Arias-Santiago $S$ et al in an observational case-control study found strong association between the presence of AGA and benign prostatic hyperplasia with odds ratio of $5.14 .^{5}$

Male pattern baldness is an androgen dependent disorder in adult men. Though the pathogenesis is not well understood, it is believed that the androgens 
act on the hair follicle via the mesenchyme- derived dermal papilla present in the middle of the hair follicle bulb. ${ }^{15}$ The patients having autosomal recessive genetic disorder of $5 \alpha$-reductase deficiency do not develop Androgenetic Alopecia, which suggests that DHT is the androgen responsible for it. ${ }^{16}$ Dihydrotestosterone, an androgen controls the normal growth and secretory functions of the prostate gland, thus maintains Benign Prostatic hyperplasia (BPH).

The prevalence of AGA increases steadily with advancing age. High prevalence has been found among men of white race/ethnicity, whereas lower prevalence has been seen among Asians, Native American, and African American men. Increased risk of AGA with age reflects the natural progression of this condition. ${ }^{17}$

In AGA gradual thinning in the temporal areas are present, producing a reshaping of the anterior hairline. ${ }^{18}$ By the age of 20 years, more than $90 \%$ of men demonstrate some degree of fronto-parietal recession of hairline. ${ }^{19}$ Among our study population, 138 (78.4\%) patients had frontal region involvement followed by vertex involvement observed in 53 (30.1\%) patients of AGA. Rate of progression is influenced by genetic predisposition. ${ }^{20}$

In our study, out of total 34 patients having precipitating factor for androgenetic alopecia, emotional stress was the major precipitating factor found in 20 (66.7\%) patients. Stress responses, mediated by typical stress hormones, like catecholamines, prolactin, Adrenocoticotrophic hormone (ACTH), Corticotrophin Releasing Hormone (CRH), b-endorphins, glucocorticoids, and substance P directly and indirectly alter hair growth by interacting and disturbing the release of the various neuropeptides. ${ }^{9}$

The genetic inheritance of AGA has been documented well in the literature, but only few studies have been done regarding familial aggregation of AGA. Also, one gene that encodes for androgen receptor in gene polymorphism of AGA has been identified. ${ }^{17}$ Our study also reports that male relatives were more prone to have AGA if there were young family members with AGA.

The various diseases associated with AGA are benign prostatic hyperplasia, ${ }^{4,5}$ hypertension, ${ }^{6}$ obesity, ${ }^{6}$ dyslipidemia, ${ }^{6}$ insulin resistance ${ }^{7,8}$ and cardiovascular diseases. $^{7}$ In our study, three patients (1.7\%) in case group had diabetes mellitus. This finding is in corroboration with two studies Matilainen VA et $\mathrm{al}^{7}$ and González-González JG et $\mathrm{al}^{8}$ that showed association of diabetes mellitus due to insulin resistance in AGA.
Similarly, $3(1.7 \%)$ patients had benign prostatic hyperplasia and this finding is in corroboration with few studies. ${ }^{5,12-14}$ Only 1 (0.56\%) patient had hypertension. Association between AGA and hypertension has been shown in several previous studies. . $^{6,70,21}$

The difference in the blood pressure might be due to the androgens binding to mineralocorticoid receptors, which may be responsible for development of hypertension in men as compared to women. ${ }^{22}$ Also hyperaldosteronism which has been found to be causative factor for primary hypertension in literature, may directly lead to the development of alopecia. ${ }^{21}$ In our study, only one (0.6\%) patient had Systolic BP $\geq 140 \mathrm{~mm} \mathrm{Hg}$ and five cases (2.8\%) had Diastolic BP $\geq 90$ $\mathrm{mm} \mathrm{Hg}$. This finding is in contrast to the study done by Ahouansou $S$ et al who found strong association between Androgenetic alopecia and hypertension. ${ }^{21}$ The majority of younger population in our study could explain this finding.

Berry SJ et al reported that $50 \%$ of men develop $\mathrm{BPH}$ by the sixth decade of life, which rises to $70 \%$ and $90 \%$ by the seventh and ninth decade respectively. ${ }^{23}$ With increase in literacy, general awareness of prostatic disease will increase leading to rise in the number of BPH patients. Boyle $\mathrm{P}$ reported that by the end of the century, men population are expected to have an $88 \%$ chance of developing $\mathrm{BPH}$ and above $50 \%$ chance of developing symptoms, and thus male pattern baldness. ${ }^{24}$ In our study only $1.7 \%$ of the cases had BPH, among them two had grade III and one had grade IV male pattern baldness. This may be because patients with AGA were of younger age than in other studies. ${ }^{23,24}$

It is evident from the previous studies that the volume of prostate increases with increasing age and common after $4^{\text {th }}$ decade of life, ${ }^{23,24}$ which is comparable with our study as mean prostate size was found to be greater in case group $\left(11.15 \mathrm{~cm}^{3}\right)$ as compared to control group $\left(6.24 \mathrm{~cm}^{3}\right)$. This is in corroboration with the study done by Chen $\mathrm{W}$ et al, who found high prevalence of alopecia in patients with more than $30 \mathrm{~cm}^{3}$ prostate size as compared to smaller prostate ( $83.3 \%$ vs. $61.3 \%$, p value $<0.05) .{ }^{11}$ In this study prostate size was mildly larger, but not significantly higher in AGA patients in comparison to the controls ( 42.7 vs. $35.4 \mathrm{~cm}^{3}$ ) and it did not differ with grading of alopecia (NorwoodHamilton scale).

In our study, 17 patients (9.7\%) in case group and four patients $(3.4 \%)$ in control group were moderately/ severely symptomatic. Though result was significant in bivariate analysis with $p$ value $=0.042(\mathrm{Cl}: 0.98-9.21)$, 
but it was not statistically significant in multivariate analysis.

It is in corroboration with the study done by AriasSantiago $S$ et al in which AGA patients with larger prostate volume had early change in urinary flow and higher IPSS. ${ }^{5}$

Cigarette smoking causes damage to the vascular supply of the dermal hair papilla and also to the DNA of the hair follicles. Smoking also causes proinflammatory cytokines release due to oxidative stress resulting in follicular microinflammation and fibrosis. Cigarette smoking can lead to antiprotease system imbalance and also hypoestrogenic state. ${ }^{1}$

In our study, we found that AGA was not associated with cigarette smoking as $62.5 \%$ of the cases were non-smokers, $12.5 \%$ had either quit smoking and $25 \%$ were current smokers.

\section{Conclusion}

We can conclude that positive family history of the androgenetic alopecia increases the chances of developing androgenetic alopecia in men though with increasing age. No association between androgenetic alopecia and benign prostatic alopecia could be elicited from our study. But majority of patients in our study were of younger age group and $\mathrm{BPH}$ is not a common finding of younger age group. Further multicenter studies with a larger sample size to evaluate the association of Benign prostatic hyperplasia (BPH) and other risk factors with androgenetic alopecia (AGA) is recommended.

\section{Acknowledgements}

We sincerely thank Dr. Surya Raj Niraula and $\mathrm{Mr}$ Surendra Uranw for their help for assistance in the statistical analysis.

Financial disclosure: None.

Conflicts of interest to disclosure: None declared.

\section{References}

1. Trüeb RM. Molecular mechanisms of androgenetic alopecia. Exp Gerontol 2002;37(8-9):981-90. https://doi.org/10.1016/S0531-5565(02)00093-1

2. Norwood OT. Male pattern baldness: classification and incidence. South Med J 1975;68(11):1359-65. https://doi.org/10.1097/00007611-19751100000009

3. Lesko SM, Rosenberg L, Shapiro S. A case-control study of baldness in relation to myocardial infarction in men. JAMA 1993;269(8):998-1003. https://doi.org/10.1001/jama.269.8.998

4. Eaton CL. Aetiology and pathogenesis of benign prostatichyperplasia. Curr Opin Urol 2003;13(1):7$10 . \quad$ https://doi.org/10.1097/00042307200301000-00002

5. Arias-Santiago $S$, Arrabal-Polo MA, BuendíaEisman A, Arrabal-Martín M, Gutiérrez-Salmerón MT, Girón-Prieto MS, et al. Androgenetic alopecia as an early marker of benign prostatic hyperplasia. J Am Acad Dermatol 2012;66(3):401-8. https:// doi.org/10.1016/j.jaad.2010.12.023

6. Matilainen V, Koskela P, Keinänen-Kiukaanniemi S. Early androgenetic alopecia as a marker of insulin

resistance. Lancet 2000;356(9236):1165-6. https://doi.org/10.1016/S0140-6736(00)02763-X

7. Matilainen VA, Mäkinen $P K$, KeinänenKiukaanniemi SM. Early onset of androgenetic alopecia associated with early severe coronary heart disease: a population-based, case-control study. J Cardiovasc Risk 2001;8(3):147-51. https:// doi.org/10.1097/00043798-200106000-00005

8. González-González JG, Mancillas-Adame LG, Fernández-Reyes $M$, Gómez-Flores $M$, LavalleGonzálezFJ, Ocampo-CandianiJ, etal. Androgenetic alopecia and insulin resistance in young men. Clin Endocrinol 2009;71(4):494-9. https://doi. org/10.1111/j.1365-2265.2008.03508.x

9. Botchkarev VA. Stress and the hair follicle: exploring the connections. Am J Pathol 2003;162(3):709-12. https://doi.org/10.1016/ S0002-9440(10)63866-7

10. Rebora A. Baldness and coronary artery disease: the dermatologic point of view of a controversial issue. Arch Dermatol 2001;137(7):943-7. doi:101001/pubs.Arch Dermatol.-ISSN-0003-987x-1377-dre0006

11. Chen W, Yang CC, Chen GY, Wu MC, Sheu HM, Tzai TS. Patients with a large prostate show a 
higher prevalence of androgenetic alopecia. Arch Dermatol Res 2004;296(6):245-9. https://doi. org/10.1007/s00403-004-0514-z

12. Bingham KD, Shaw DA. The metabolism of testosterone by human scalp skin. J Endocrinol 1973;87:111-21. https://doi.org/10.1677/ joe.0.0570111

13. Dallob AL, Sadick NS, Unger W, Lipert S, Geissler LA, Gregoire SL, et al. The effect of finasteride, a $5 \alpha$ - reductase inhibitor, on scalp skin testosterone and dihydrotestosterone concentrations in patients with male pattern baldness. J Clin Endocrinol Metabol 1994;79:703-6. https://doi. org/10.1210/jcem.79.3.8077349

14. Oh BR, Kim SJ, Moon JD, Kim HN, Kwon DD, Won $\mathrm{YH}$, et al. Association of benign prostatic hyperplasia with male pattern baldness. Urology 1998;51(5):744-8. https://doi.org/10.1016/ S0090-4295(98)00108-3

15. Randall VA, Hibberts NA, Hamada K. A comparison of the culture and growth of dermal papilla cells from hair follicles from non-balding and balding (androgenetic alopecia) scalp. $\mathrm{Br} J$ Dermatol 1996;134:437-44. https://doi.org/10.1046/ j.1365-2133.1996.28763.x

16. Anderson S, Berman DM, Jenkins EP, Ruxxel DW. Deletion of steroid 5 alpha-reductase 2 genein male pseudohermaphroditism. Nature 1991;354:15961. https://doi.org/10.1038/354159a0

17. Su LH, Chen TH. Association of androgenetic alopecia with smoking and its prevalence among
Asian men: a community-based survey. Arch Dermatol 2007;143(11):1401-6. https://doi. org/10.1001/archderm.143.11.1401

18. Thomas J. Androgenetic alopecia: Current status. Indian J Dermatol 2005;50:179-90. http://www.eijd.org/text.asp?2005/50/4/179/19741

19. Hamilton JB. Patterned loss of hair in man; types and incidence. Ann N Y Acad Sci 1951;53(3):70828. https://doi.org/10.1111/j.1749-6632.1951. tb31971.x

20. Stough DB, Rao NA, Kaufman KD, Mitchell C. Finasteride improves male pattern hair loss in a randomized study in identical twins. Eur J Dermatol 2002;12:32-7. PMID: 11809593

21. Ahouansou S, Le Toumelin P, Crickx B, Descamps V. Association of androgenetic alopecia and hypertension. Eur J Dermatol 2007;17(3):220-2. https://doi.org/10.1684/ejd.2007.0152

22. Quinkler $M$, Diederich $S, B a h r ~ V$, and Oelkers $\mathrm{W}$. The role of progesterone metabolism and androgen synthesis in renal blood pressure regulation. Horm Metab Res 2004;36:381-6. https://doi.org/10.1055/s-2004-814572

23. Berry SJ, Coffey DS, Walsh PC, Ewing LL. The development of human benign prostatic hyperplasia with age. J Urol 1984;132:474-9. https://doi.org/10.1016/S0022-5347(17)49698-4

24. Boyle P and Napalkov P: The epidemiology of benign prostatic hyperplasia and observations on concomitant hypertension. Eur Urol 1996;29(suppl):7-11. PMID: 7541551. 